subject of resistance to penicillin was interesting. Some of the members present had seen cases which had failed to respond to quite large doses. He had heard of one case in which there was a double infection of syphilis and gonorrhoea; in this case the syphilis appeared to be cured but the gonorrhoea persisted in spite of treatment with $2,400,000$ units of penicillin.

\title{
REFERENCES.
}

Beveridge, W. I. B. (1943) Med J. Aust., 2; 479.

Dienes, L. (1940) Pro, Soc. exp. Biol., N.Y., 44, 468.

and Smith, W. E. (1942) ibid., 50. 99.

Harkness, A. H. (1945) Brit. J. vener. Dis., 21, 93.

Jones, T. R. L. and Maitland, F. G. (1945) Brit. J. vener. Dis., 21, 65.

Lapenta, R. G., Weckstein, A. M., and Sarnoff, H. (1945) J. Amer. med. Ass., 128, 168.

Powell, H. M., and Rice. R. M. (1914) J. Lab. clin, Med, 29. 372.

Selbie, F. R. and Simon, R. D. (1944) Brit. J. exp. Path., 25, 229.

\section{GUMMA OF THE THYROID GLAND}

\author{
By SYDNEY M. LAIRD, B.Sc., M.D., Ch.B., F.R.F.P.S., D.P.H. \\ Major, R.A.M.C. : Western Command Specialist in Venereal Diseases.
}

Gumma of the thyroid gland is rare; Stokes has seen the condition only twice. A number of individual cases, however, have been reported and the following one is typical.

\section{Case report}

A soldier aged 42 years reported sick with a swelling in the neck which he had noticed for the past year. He was transferred to my. care on 22nd March 1945 ; as a routine Wassermann test had given a positive reaction; the tentative diagnosis given was a branchial cyst. In addition to the painless swelling, he reported increasing difficulty over the past 12 months in swallowing solid or dry food, together with undue breathlessness on exertion.

History.-His father had tabes dorsalis. His mother had had 3 pregnancies ; the patient was the last child and was preceded by a sister who died in infancy. He had been married for 20 years and his wife's first child died "from pneumonia" at the age of 6 weeks. Two miscarriages followed. He denied having had venereal disease.

Examination.-Examination revealed a painless, non-tender, rather soft swelling underlying the left sternomastoid muscle in the anterior triangle of the neck. It was not pulsatile, moved slightly when he swallowed and did not appear to infiltrate the surrounding structures. The trachea was displaced to the right. The tumour was the size of a plum, and the glands in the posterior triangle of the left side of the neck were palpable, firm, nontender and discrete. The patient was edentulous and showed anterior bowing of the tibiae ; no other stigma of congenital syphilis was noted. He was dull, apathetic and had some thinning of the outer parts of the eyebrows, but showed no other clinical evidence of myxoedema. No other abnormality was detected and there was no penile scar.

The blood Wassermann and Kahn tests were both strongly positive ; the cerebrospinal fluid was normal. Radiological examination showed the following: (1) some increased periosteal thickening of both tibiae and fibulae with a generally increased density of the left tibia ; (2) bronchitis and some dilatation of the aorta and displacement of the trachea to the right ; (3) a barium swallow showed no evidence of a diverticulum, the bolus passing without difficulty through the oesophagus, which was however pushed over to the right by the swelling.

Treatment.-A diagnosis of congenital syphilis was made and it was decided to undertake a therapeutic test to exclude gumma of the thyroid gland. Sodium iodide administration was cormmenced cautiously and later increased to a daily dosage of 90 grains. Bismuth oxychloride, 0.2 gramme, was given every 5 days and on the eleventh day of treatment small doses of mapharside were commenced. An excellent therapeutic response was obtained. On the eleventh day of treatment the thyroid swelling was decidedly diminished and the patient was mentally brighter. One month later only a small nodule could be felt in the left lobe of the thyroid, and 3 months after the institution of antisyphilitic treatment even this was no longer palpable. The general improvement, physical and mental, was marked and the eyebrows had returned to normal.

Literature of gumma of the thyroid gland

In congenital syphilis,

In 1866 Lancereaux wrote: "We do not know of any case which gives evidence 


\section{GUMMA OF THE THYROID GLAND}

of a gummous deposit in the substance of the thyroid gland"', but Demme, 10 years later, reported 3 cases, all in children, in which the gummatous nodules in the thyroid were associated with other syphilitic visceral lesions. Barth and Gombault in 1884 described one case of congenital syphilis with interstitial keratitis, tibial nodes and swelling of the thyroid. Section of the latter showed nodules possessing a thick wall of connective tissue containing a few giant cells, a caseous centre and marked endarteritis obliterans of the vessels. In more recent times Lasch reported a solid tumour of the thyroid in a girl aged 18 years, with enlarged lymph glands and positive Wassermann reaction, the gummatous nature of which was proved by section. Stropeni discussed the diagnosis of late syphilis of the thyroid and reviewed the literature; he reported a personally observed case of congenital syphilis in a girl aged 15 years. Menninger described 3 cases in which the thyroid was of normal size but section showed interstitial fibrosis and small vesicles; all the children were suffering from congenital syphilis and their ages were one month, 9 years and 17 years, respectively. He stresses the importance of syphilis as a factor in causing hypothyroidism in congenital syphilitic patients. Gordon found evidence of syphilis in 5 out of 42 children with diminished thyroid secretion.

\section{In the dead foetus}

Perrando, in a histological study of the thyroid in syphilitic foetuses, found in all his cases structural changes which he considered to be of diagnostic significance, including small cell infiltrations, endarteritis obliterans, reduction of colloid material and arrested development of thyroid parenchyma. Glandular enlargement was caused by hypertrophy. of interstitial connective tissue.

\section{In acquired syphilis : tertiary stage}

Gumma of the thyroid gland may occur also in acquired syphilis. Fraenkel described in 1887 a gumma of the thyroid isthmus in a woman aged 41 years; at necropsy, ulcerating gummata of trachea, bronchi, liver and kidneys were found. Köhler in 1892 described gumma of thyroid associated with myxoedema in a woman aged 43 years; both conditions responded to iodide therapy. Pospelow in 1894 reported a male case, aged 45 years, with thyroid gumma, myxoedema and diabetes insipidus. In 1897, Clarke described the case of a woman aged 38 years.

She had dysphagia, dyspnoea and hoarseness, associated with a hard, cylindrical mass extending from the hyoid bone to the manubrium sterni in the midline, which moved when the patient swallowed. Gummatous ulceration occurred in its upper part. She had been treated 4 years earlier for gummata of arm and face. Tracheotomy became necessary, but the tumour subsequently abated rapidly with potassium iodide medication.

In 1898 Küttner reported 2 cases.

The first was a male aged 27 years who had had goitre in childhood. A tumour developed in the right lobe of the thyroid, becoming the size of a fist and causing displacement of the trachea to the left with stridor, dyspnoea, and palsy of the right recurrent laryngeal nerve. At operation the tumour was too firmly adherent to the trachea to permit of excision, but it disappeared rapidly after subsequent treatment with iodides.

Küttner's second case was a woman who had had a small goitre since childhood and had contracted syphilis at the age of 18 years. When 39 years old she presented a tumour of the left lobe of the thyroid gland, which had been noticed for 4 months. It extended from the angle of the jaw to the sternum, was movable, nodular and very hard, and caused stridor and palsy of the left recurrent laryngeal nerve. The overlying skin was intact and the cervical glands were enlarged. Carcinoma was diagnosed and excision performed; a section indicated syphilis. Five months later ulceration of the soft palate occurred, which responded rapidly to iodide therapy; she was well 5 years later.

Hültl reported gumma of the left lobe of the thyroid in a male case, aged 58 years, with dyspnoea, dysphagia, hoarseness and emaciation. Malignancy was diagnosed and tracheotomy was required. Biopsy of the tracheotomy wound indicated syphilis and the swelling disappeared with iodides. Wermann reported a male case aged 24 years. For 5 years after contracting syphilis he showed many specific manifestations, and in the sixth year a soft, symmetrical, painless and 


\section{THE BRITISH JOURNAL OF VENEREAL DISEASES}

symptomless swelling of the thyroid rapidly developed. It responded quickly to treatment with mercury. .

\section{In 1906 Mendel reported 3 cases.}

They were all females, two aged 38 years and the third 63 years. The first died from heart failure 2 days after tracheotomy and excision; sýphilis of spleen and liver was noted at autopsy. The second patient's tumour disappeared with iodide therapy. In the third patient administration of iodides caused the tumour to disappear, but 3 months later it reappeared and she died after a further 6 weeks from malignant change in the thyroid.

Thursfield's case in 1908 was a man aged 53 years.

He had had 6 months' treatment for syphilis some 30 years previously, followed by the appearance of tertiary lesions which responded to iodide medication. He later developed a tumour of the right lobe of the thyroid gland, which was painless, hard, smooth, oval in shape with a rounded margin, and measured $2 \times 1$ inches. The skin was intact and the tumour disappeared completely with further administration of iodides.

Power in the same year described a female case aged 53 years.

The patient had contracted syphilis 30 years previously and presented numerous signs of tertiary syphilis. A hard, painless, smooth tumour developed in the right lobe of the thyroid. It measured $2 \times 1$ inches, was not adherent to the skin and did not move when she swallowed. It disappeared after one month of iodide therapy.

In 1910, Davis reviewed 20 cases of tertiary syphilis of the thyroid, including one which he had observed, but in some the diagnosis was not well established.

Sebileau a year later reported 2 cases.

The first was a female aged 28 years with a hard, painless swelling of the thyroid the size of an orange. Excision was unsuccessful on account of its attachment to the trachea, but a speedy recovery followed the use of mercury and iodides. The second case was a male, age not stated, with a hard tumour of the thyroid. Malignancy was suspected but the swelling disappeared with antisyphilitic treatment.

Poncet and Leriche in 1912 reported a female case aged 38 years and stated, in addition, that Feuille had first demonstrated Spirochaeta pallida in thyroid lesions 4 years earlier.

Joll, writing in 1932, had seen his only case in 1915 .

The patient was aged 34 years and had had 3 miscarriages and 2 infants who died of convulsions. There was one apparently healthy child aged 13 years. The patient had a smooth, very hard swelling of the right lobe of the thyroid gland. Symptoms had been present for over 6 months and included palpitations, dyspnoea, dysphagia, hoarseness and loss of weight. At operation the tumour was found to be adherent to surrounding structures and compressing the trachea ; it weighed $1 \mathrm{oz}$., measured $2 \times 1 \frac{3}{4}$ inches and showed central necrosis. No evidence of tuberculosis was noted in the section, which showed giant cells and an extreme degree of endarteritis obliterans. The blood Wassermann reaction was strongly positive. The operation wound broke down, but healed rapidly with antisyphilitic treatment.

In 1917, Thompson reported the case of a male aged 72 years, who gave a history of syphilis.

He had a painless movable tumour of the right lobe of the thyroid gland, measuring $4 \times 1 \frac{1}{2}$ inches. There was slight protrusion of the eyes, tachycardia, albuminuria and a raised blood pressure. The blood Wassermann reaction was strongly positive. The tumour and the other abnormal findings disappeared after 6 weeks' treatment with mercury and iodides.

Schneider reported a case of gumma of the right lobe in a woman aged 48 years.

She had had a thyroid adenoma from the age of 17 years, and gave a history of syphilis ; the Wassermann reaction was positive. The adenoma became enlarged, causing pressure symptoms and suggesting malignant degeneration. Section indicated syphilis, however, and antisyphilitic treatment was followed by recovery.

In 1918, Simonton reported 5 cases in which he thought syphilis was the cause of thyroid disease ; in one a gumma was probably present. In the same year, Senear reviewed the literature and described one male case seen by him 2 years earlier.

Senear's case presented gummatous ulceration over the upper end of the sternum and both sternoclavicular joints, connected by a sinus with a tumour of the left lobe and isthmus of the thyroid gland. The anterior cervical glands were involved and both testes had hard 


\section{GUMMA OF THE THYROID GLAND}

nodules. It is probable that the patient had had secondary syphilis some 7 years previously ; the Wassermann reaction was strongly positive. No biopsy was done, but all lesions responded well to treatment with iodides and salvarsan (arsphenamine).

Williams and Steinberg reported 2 female cases, aged 60 and 44 years respectively. In both cases firm nodules were present in the thyroid, section indicated gumma and there was a good therapeutic response.

Groedel and Hubert described one female case aged 46 years.

There was a diffuse, painful swelling of the whole gland and a hard nodule in the right lobe. Pressure symptoms and aortic insufficiency were present. The Wassermann reaction was positive. Treatment with Neosalvarsan (neoarsphenamine) produced a rapid disappearance of the swelling and symptoms.

Netherton in 1932 reviewed the literature, analysed 62 case records and attempted to assess the relationship of syphilis to thyroid disease.

His cases included one example of gumma of thyroid in a coloured male aged 30 years. He had acquired syphilis 14 years previously, receiving only 3 injections of Neosalvarsan 5 years after his initial infection. He had a tumour of the left side of the neck, which was tender and caused dysphagia. It was firm, irregular and attached to the trachea and sternomastoid. It moved on swallowing and was unattached to the overlying skin. The Wassermann reaction was strongly positive. After 5 injections of Neosalvarsan the swelling had almost disappeared.

Incedayi reported an advanced case of ulcerating gummatous thyroiditis in a woman aged 50 years, which developed 14 years after syphilitic infection; the response to Neosalvarsan was excellent.

\section{In acquired syphilis : secondary stage}

Generalized enlargement of the thyroid gland occurring in adults during the secondary stage of syphilis has been reported by Engel-Reimers and by Lockwood, also by Wile in the discussion on the paper read by Netherton. In some cases prompt recovery follows antisyphilitic treatment, thus suggesting a true specific thyroiditis. When symptoms of hyperthyroidism appear during secondary syphilis but remain unrelieved by antisyphilitic treatment, Wile regards these cases as potential hyperthyroidism in which syphilis acts as a precipitating factor in the same way as may fright, emotional disturbance and severe illness.

\section{Comment}

A study of the literature indicates that syphilitic lesions of the thyroid gland may occur at any age. Gumma, usually single, is the commonest lesion and may develop 1-30 years after acquired or prenatal infection. Any part of the thyroid may be involved, but the condition is usually unilateral. In the early stages of development the swelling is smooth, hard, painless and movable. The related lymphatic glands may be enlarged. As surrounding structures become involved, mobility is reduced and pressure symptoms occur; these may include dyspnoea, dysphagia and palsy of the recurrent laryngeal nerve. Tracheotomy may be required. Disturbance of thyroid function, usually myxoedema, may occur. When myxoedema is associated with syphilis the cerebrospinal fluid findings should be interpreted cautiously, as the protein is often increased in myxoedema (Moore). Gumma of the thyroid gland has been reported more often in females than in males. The Wassermann reaction is usually positive and there may be other clinical manifestations of late syphilis.

The differential diagnosis includes malignant disease, tuberculosis and chronic thyroiditis (Riedel's disease). Diagnosis is assisted by a history or other evidence of syphilis, positive serological tests and the response to a therapeutic test. Treatment is usually rapidly effective, but Joll favours early operation when diagnostic doubt exists because there may be an initial response in malignant cases. Treatment, especially with iodides, should be particularly cautious when symptoms of hyperthyroidism are present. 


\title{
THE BRITISH JOURNAL OF VENEREAL DISEASES
}

\section{Summary}

A case of gumma of the thyroid gland is reported and the literature is reviewed.

I am indebted to Dr. J. Laurie, Medical Superintendent, Sharoe Green Hospital, Preston, Lancashire, for the radiological investigation and reports of the case reported on by myself.

\section{REFERENCES}

Barth, A. and Gombault, F. A. A. (1884) Progr. méd.; Paris, 12, 834.

Clarke, B. (1897) Lancet, 2, 389.

Davis, B. F. (1910) Arch. intern. Med., 5, 47.

Demme, R. (1878) Gerhardt's Handbuch der Kinderkrankheiten, III, 337.

Engel-Reimers, J. (1894) Jb. hamburg. St.Kr.Anst., 3, 430.

Fraenkel, E. (1887) Dtsch. med. Wschr., 13, 1035.

Gordon, M. B. (1922) N.Y. St. J. Med., 115, 350.

Groedel, F. M., and Hubert, G. (1925) Schweiz. med. Wschr., 55, 674.

Hültl, H. (1899) Pester med.-chir. Pri., 35, 442.

Incedayi, C. K. (1939) Dermatologia, 79, 214.

Joll, C, A. (1932) Diseases of the Thyroid Gland, with Special Reference to Thyrotoxicosis, London, pp. 91-96.

Köhler, R. (1892) Berl. klin. Wschr., 29, 743.

Küttner, H. (1898) Beitr. klin. Chir., 22, 517.

Lancereaux, E. (1866) Traité historique et pratique de la syphilis, Paris. (English translation by $\mathrm{G}$. Whitley, 1868).

Lasch, C. H. (1925) Zbl. Chir., 52, 738.

Lockwood, C. B. (1895) St. Bart's Hosp. med. Rep., 31, 232.

Mendel, F. (1906) Med. Klin., 2, 833.

Menninger, 'W. C. (1929) Amer. J. Syph., 13, 164.

Moore, J. E. (1944) Modern Treatment of Syphilis, 2nd edition, London, p. 468.

Netherton, E. W. (1932) Amer. J. Syph., 16, 479.

Perrando, G. G. (1902) Gazz. Osp. Clin., 23, 186.

Poncet, A., and Leriche, R. (1912) Bull. Soc. Chirurgie Paris, 38, 783.

Pospelow, A. (1894) Mschr. prakt. Dermatol., 19, 125.

Power, D'A., and Murphy, J. K. (edited by) (1908) System of Syphilis, 1st edition, London, II, 166.

Schneider, E. H. (1918) Calif. St. J. Med., 16, 484.

Sebileau, P. (1911) Bull. Soc. Chirurgie, Paris, 37, 1305.

Senear, F. E. (1918) Amer. J. med. Sci., 155, 691.

Simonton, T. G. (1918) Penn. med. J., 21, 293.

Stokes, J. H., Beerman, P., and Ingraham, N. R., Jun. (1914) Modern Clinical Syphilology, 3rd edition, Philadelphia and London, p. 1322.

Stropeni, L. (1927) Ann. ital. Chir., 6, 587.

Thompson, L. (1917) Amer. J. Syph., 1, 179.

Thursfield, R. M. R. (1908) Brit. med. J., 1, 147.

Wermann, E. (1900) Berl. klin. Wschr., 27, 122.

Williams, C., and Steinberg, B. (1924) Surg. Gynec. Obstet., 38, 781.

\section{INTENSIVE ARSENOTHERAPY ÖF EARLY SYPHILIS*}

\author{
By T. R. LLOYD JONES, M.R.C.S., L.R.C.P.
}

Surgeon Captain, Royal Navy; Consultant in Venereal Diseases, Royal Navy

$$
\text { and F. GORDON MAITLAND, M.R.C.S., L.R.C.P. }
$$

Surgeon Lieutenant Commander, Royal Naval Volunteer Reserve

Since World War II began a notable increase in the incidence of venereal disease has been recorded, bringing in its wake sociological and economic consequences. In the Forces these problems, especially as regards early syphilis, brought us to the point at which it was undoubtedly necessary that previous methods of treatment, often involving a big wastage of man-hours, should be revised, in order that some saving could be made in this direction and that men suffering from syphilis could be cured as quickly as possible. This problem

\footnotetext{
- An address to the Medical Society for the Study of Venereal Disease, 24th March, 1945.
} 